\title{
The Child and Adult Care Food Program: Barriers to Participation and Financial Implications of Underuse
}

\author{
Tatiana Andreyeva, $\mathrm{PhD}^{1}$; Xiaohan Sun, $\mathrm{PhD}^{2}$; Mackenzie Cannon, $\mathrm{RD}, \mathrm{CDN}^{3}$; \\ Erica L. Kenney, $\mathrm{ScD}^{4}$
}

\begin{abstract}
Objective: To assess facilitators and barriers to participation in the Child and Adult Care Food Program (CACFP) and estimate foregone federal funds because of CACFP underuse.

Methods: An online survey of food service practices and experiences with CACFP among Connecticutbased licensed child care centers $(n=231)$.

Results: Serving meals and the center's nonprofit status predicted CACFP participation. The most common challenge among participants was collecting family income eligibility. Streamlining paperwork (mentioned by $44 \%$ of respondents) and funding for nonfood, administrative costs (40\%) were recommended facilitators to increase CACFP uptake. Nonparticipating centers had limited knowledge about the program and its eligibility. Foregone federal funding due to CACFP underuse among eligible Connecticut centers was estimated at $\$ 30.7$ million in 2019 , suggesting that 20,300 young children from low-income areas missed out on CACFP-subsidized food.

Conclusions and Implications: Improving knowledge about CACFP and reducing participation burdens through additional funding and technical assistance can help expand the program to support child nutrition. Key Words: child care, food assistance, CACFP, preschool-age children, food policy (J Nutr Educ Behav. 2022;54:327-334.)
\end{abstract}

Accepted October 4, 2021. Published online December 2, 2021.

\section{INTRODUCTION}

Child nutrition in the US is in a crisis, with millions of children at risk for poor diet, unhealthy weight gain, and food insecurity. ${ }^{1-4}$ Early Care and Education (ECE) settings, such as child care centers and family child care homes, can improve children's diets by serving nutritious foods and beverages and implementing feeding practices that encourage healthy choices. $^{5-8}$ Their impact could be wide-reaching as most young American children spend days in regular nonparental care. ${ }^{9}$

A critical role in supporting nutrition in ECE settings belongs to the federal Child and Adult Care Food Program (CACFP), which served 4.6 million children before the pandemicrelated disruptions. Targeting benefits to children from low-income areas, CACFP provides meal

\footnotetext{
${ }^{1}$ Department of Agricultural and Resource Economics, Rudd Center for Food Policy and Health, University of Connecticut, Hartford, CT

${ }^{2}$ The Maxwell School of Citizenship and Public Affairs, Syracuse University, Syracuse, NY

${ }^{3}$ Rudd Center for Food Policy and Health, University of Connecticut, Hartford, CT

${ }^{4}$ Prevention Research Center on Nutrition and Physical Activity, Harvard T.H. Chan School of Public Health, Boston, MA

$\dagger$ Dr. Xiaohan Sun is currently affiliated with the Center for Policy Research, The Maxwell School of Citizenship and Public Affairs, Syracuse University, Syracuse, NY.

Conflict of Interest Disclosure: The authors have not stated any conflicts of interest.

Address for correspondence: Tatiana Andreyeva, PhD, Department of Agricultural and Resource Economics, Rudd Center for Food Policy and Health, University of Connecticut, One Constitution Plaza, Hartford, CT 06103; E-mail: tatiana.andreyeva@uconn.edu

(C) 2021 The Authors. Published by Elsevier Inc. on behalf of Society for Nutrition Education and Behavior. This is an open access article under the CC BY-NC-ND license (http:// creativecommons.org/licenses/by-nc-nd/4.0/)

https://doi.org/10.1016/j.jneb.2021.10.001
}

reimbursements on a sliding scale and sets nutrition standards for food served. ${ }^{10}$ The CACFP has multiple benefits to its constituents: children obtain nutritious foods that are served using recommended feeding practices ${ }^{11-17}$; families save up to $\$ 30.95$ in weekly food costs per child $^{18}$; providers receive financial support from reimbursements, free nutrition training, and access to commodity foods. ${ }^{10}$

Despite its advantages, CACFP is not used by many eligible child care providers, leaving young at-risk children without CACFP benefits. Research to understand the extent of CACFP underuse and gaps in coverage is just beginning to emerge. There are multiple potential reasons why CACFP does not reach many eligible programs and children. In 1 Connecticut study, more than half of 256 licensed non-CACFP centers did not know about CACFP, even though many were eligible and all were supposed to implement CACFP nutrition standards per state licensing regulations. ${ }^{12}$ Program application and compliance could be costly and 
difficult to navigate. ${ }^{19,20}$ There is a paucity of data on the motivation of ECE providers to participate in CACFP, including how their decisions affect access to CACFP across states and population groups. ${ }^{21}$

This study aimed to identify facilitators and barriers to CACFP participation to expand the CACFP reach and improve the nutrition of young children. Using data from an online survey of licensed child care centers in Connecticut, the study analyzed predictors of CACFP participation, assessed program experiences, knowledge and challenges, reasons for not participating, and opinions about increasing the program appeal. The study's secondary goal was to estimate the amount of foregone federal funding because of CACFP underuse.

\section{METHODS}

\section{Data and Sample Selection}

The sample was Connecticut-based licensed child care centers that served meals and/or snacks to children aged 0-5 years. The study used administrative data from the Office of Early Childhood on capacity, ages served, contact information, and nonprofit/for-profit status of licensed child care centers. Census-block data from the 2013-2017 American Community Survey ${ }^{22}$ were used to describe center neighborhoods. Data on meal/snack service was collected through phone calls to providers.

After-school programs serving only school-age children (aged 5-12 years) were excluded. Family child care homes were not assessed because of differences in the implementation of CACFP between homes and centers. The study recruited all CACFP centers $(n=176)$ and a random sample of 391 non-CACFP centers selected from 733 non-CACFP centers serving children aged $0-5$ years and known to provide snacks/meals. Non-CACFP centers in low-income communities were oversampled.

Center directors were recruited by email with an online survey about food service practices affecting young children and center experiences with CACFP, requesting that the survey be completed by the person most familiar with the center's food service (eg, center director). All participants received a \$20 gift card for survey completion. The study was approved by the University of Connecticut Institutional Review Board (IRB) and the CT Office of Early Childhood IRB in December, 2018.

\section{Measures and Analyses}

The survey was developed on the basis of input from informal key interviews with 11 ECE stakeholders selected from research partners or active participants in the field. These included directors of centers new to CACFP, long-time CACFP participants, centers not participating in the program, a CACFP agency staff member, a sponsor, and a nutrition consultant working with centers on CACFP compliance. Interviews were completed by 2 members of the research team (M.C. and T.A.) using a prespecified protocol. Participants' descriptions of their experiences with CACFP, including recurrent challenges, training opportunities, and participation incentives, guided the survey's development (no formal qualitative analysis was conducted). The survey was informed by our prior work $^{12}$ and research elsewhere. ${ }^{19} \mathrm{~A}$ copy of the survey is available in the Supplementary Data.

The survey assessed meals/snacks served, CACFP participation, Head Start status, accreditation with the National Association for the Education of Young Children (NAEYC), acceptance of child care subsidies, and receipt of state funding. Providers also reported on food preparation, menu development, food service facilities and equipment, and nutrition training received. Nonparticipating centers were asked about their knowledge and experience with CACFP, including eligibility, reasons for nonparticipation, and interest in future participation. For CACFP centers, the survey assessed the history of participation, its benefits and challenges, effects of the updated CACFP meal patterns, and opinions about making the application process and program participation easier.

Bivariate analyses (2-sample $t$ tests) were used to compare CACFP and nonparticipating centers. A logistic multivariate regression model was used to assess predictors of CACFP participation, including center capacity, meals/snacks served, nonprofit status, receipt of subsidies and state funding, NAEYC accreditation, and neighborhood characteristics. All analyses were conducted in Stata (version 15, StataCorp LP, 2017).

Estimation of foregone federal CACFP meal reimbursements was based on administrative data for the population of all licensed child care centers in Connecticut and not a survey-based sample. Nonparticipating CACFP-eligible child care centers were identified in 2 steps. First, all nonprofit, non-CACFP child care centers in Connecticut were counted $(\mathrm{n}=384)$ as these are eligible to participate in CACFP irrespective of children's family income. For-profit centers are eligible if they enroll at least $25 \%$ of children on free and reduced-price meals. ${ }^{10}$ A center's location in a high-poverty area was used to approximate the household income of enrolled families. High poverty was based on the city/town designation as eligible for the Community Eligibility Provision (CEP), that is, $\geq 40 \%$ of school-aged children qualified for free school meals. ${ }^{23}$ As household income eligibility is the same for school meals and CACFP, it is likely that for-profit centers serving families in the CEP areas would have reached a 25\% eligibility threshold for CACFP. Sensitivity analyses expanded the definition of high poverty to include near eligible CEP areas, meaning that $30.0 \%$ to $39.99 \%$ of school-age children qualified for free school meals. Only child care centers serving children aged < 5 years were considered, excluding after-school programs and family child care homes.

The number of served meals and snacks, which is the basis of federal CACFP reimbursements, was estimated on the basis of licensed capacity from administrative data. Children were assumed to miss an average of 3 weeks per year because of family vacations ${ }^{24}$ and 1 week because of illness, ${ }^{25}$ with annual attendance estimated at 241 days. All children were assumed to attend a full day, receiving 2 meals and 1 
snack. The federal fiscal year (FY) 2019-2020 meal reimbursement rates for contiguous states were used to calculate a daily reimbursement for serving breakfast, lunch, and 1 snack. ${ }^{26}$ Using the national FY 2019/ 20 data on the proportion of free, reduced-price, and paid meals served through the school meal programs and CACFP, it was estimated that $74.6 \%$ of meals would have been served at free rates, $6.3 \%$ at reducedprice rates, and $19.1 \%$ at full price rates. $^{27}$ The analysis was based on 2019 data and reflected a normal state of business before the pandemic-related disruptions in the child care industry and CACFP. ${ }^{21,26}$

\section{RESULTS}

There were 231 complete surveys, with a response rate of $41 \%$ overall (55\% for CACFP and 35\% for nonCACFP). Survey nonrespondents were not significantly different from respondents on the basis of the observed characteristics. Most (80\%) of the survey responses were from directors of child care centers, with an additional $8 \%$ from center administrators and 6\% from owners but not directors. Only a few responses were submitted by food service managers, nutritionists, or employees in similar positions.

\section{Center Characteristics and Food Services}

Of the 231 child care centers, 96 reported participation in CACFP, and 135 were nonparticipants. Almost all (98\%) of CACFP centers served meals and at least 1 snack, but only 16\% of non-CACFP centers had breakfast, and $18 \%$ served lunch $(P<0.001)$. Nonparticipating programs typically served snacks, whereas parents sent in lunch. Table 1 highlights other differences linked to CACFP participation, including higher rates of NAEYC accreditation, receipt of state funding, acceptance of child care subsidies, Head Start affiliation, and nonprofit status. CACFP centers were in areas with lower median household income and educational achievement, served more children with subsidized child care payments

Table 1. Characteristics of Connecticut Child Care Centers Serving Young Children $(n=231), 2019$

\section{Characteristics}

Meals and snacks provided, n (\%) Breakfast

Lunch

Morning snack

Afternoon snack

Age groups served, n (\%)

Infants and/or toddlers

Preschoolers

School-aged

No. of children served, mean (SE)

Infants and/or toddlers

Preschoolers

Nonprofit center, n (\%)

Program participation, n (\%)

NAEYC accreditation

State funding (school readiness)

Head Start/Early Head Start

Accept child care subsidies

Food service facilities, n (\%)

Full kitchen

Partial kitchen

Microwave(s)

Snack preparation location, n (\%)

Prepared in classrooms

Kitchen on site

Kitchen another site

Vendor/catering company

Menus prepared by, n (\%)

Center director

CACFP sponsor

Kitchen/food manager/cook

Menu planning service

Other (dietitian/teachers)

Nutrition training in the prior year, $\mathrm{n}(\%)$

Professional development (nutrition)

CACFP training

Child care subsidy training

State quality improvement system

NAP SACC/Go NAP SACC

No training

Center area characteristics, mean (SE)

Population below poverty, \%

Annual median household income, \$

Bachelor's degree or higher, \%

$$
\begin{array}{cc}
\text { Non-CACFP } & \text { CACFP } \\
n=135 & n=96
\end{array}
$$

\begin{tabular}{|c|c|}
\hline $22(16.3)$ & $91(94.8)^{\mathrm{C}}$ \\
\hline $24(17.8)$ & $89(92.7)^{\mathrm{C}}$ \\
\hline $122(90.4)$ & $21(21.9)^{C}$ \\
\hline $118(87.4)$ & $93(96.9)^{a}$ \\
\hline $96(71.1)$ & $58(60.4)$ \\
\hline 134 (99.3) & $92(95.9)$ \\
\hline $67(49.6)$ & $22(22.9)^{\mathrm{C}}$ \\
\hline $16.4(1.4)$ & $13.6(1.8)$ \\
\hline $47.0(2.9)$ & $81.8(11.8)^{b}$ \\
\hline $55(41.1)(n=134)$ & $84(89.4)(n=94)^{c}$ \\
\hline $65(49.2)(n=132)$ & $83(88.3)(n=94)^{c}$ \\
\hline $36(27.3)(n=132)$ & $67(71.3)(n=94)^{c}$ \\
\hline $0(n=132)$ & $22(23.7)(n=93)^{c}$ \\
\hline $99(73.4)$ & $90(93.8)^{C}$ \\
\hline $55(40.8)$ & $44(45.9)$ \\
\hline $54(40.0)$ & $32(33.4)$ \\
\hline $56(41.5)$ & $11(11.5)^{\mathrm{C}}$ \\
\hline
\end{tabular}

$61(45.2) \quad 13(13.9)(n=94)^{c}$

$83(61.5) \quad 53(56.4)(n=94)$

$0 \quad 8(8.5)(n=94)^{b}$

$11(8.2) \quad 20(21.3)(n=94)^{b}$

$86(63.7) \quad 15(15.7)^{c}$

$14(14.6)^{\mathrm{C}}$

$35(36.4)^{\mathrm{C}}$

$4(4.2)^{\mathrm{a}}$

$45(46.9)^{a}$

43 (31.9)

$43(31.9)$

$5(3.7)$

$49(51.1)^{\mathrm{b}}$

$90(93.8)^{\mathrm{C}}$

$24(25.0)$

$14(14.6)$

$4(4.2)$

$1(1.1)^{\mathrm{C}}$

$8(6.0)$

$50(37.0)$

$8.3(0.8)$

$91,555(3,671)$

$20.6(1.5)^{c}$

$50,054(2,296)^{c}$

$44.3(1.6)$

$27.0(2.0)^{c}$

CACFP indicates Child and Adult Care Food Program; NAEYC, National Association for the Education of Young Children; NAP SACC/Go NAP SACC, Nutrition and Physical Activity Self-Assessment for Child Care.

${ }^{\mathrm{a}} P<0.05 ;{ }^{\mathrm{b}} P<0.01 ;{ }^{\mathrm{c}} P<0.001$.

Note: Significance based on 2-sample t test.

(31\% vs $14 \%, P<0.001)$, and had more children in their care.

There was little variation in access to food facilities, except for the availability of more microwaves in non-
CACFP centers. Catering was more prevalent in CACFP centers, whereas non-CACFP centers were preparing food in the classroom or kitchen. Center directors usually prepared 
menus in non-CACFP centers, whereas dietitians, kitchen staff, or food service managers were responsible for menu development in CACFP centers.

Differences in nutrition training received by program directors were very large: $37 \%$ of the non-CACFP centers reported no training in the prior year vs $1 \%$ in the CACFP group $(P<0.001)$. Almost universal completion of nutrition training was because of the required CACFP training, and no significant differences were seen for other programs.

\section{Experience with CACFP Among Nonparticipants}

Most nonparticipating centers (67\%) acknowledged hearing about CACFP in the past, with higher rates among eligible programs (76\% vs 57\%, $P<$ 0.05). Among the programs that knew about CACFP, $81 \%$ reported that they were aware of state licensing regulations requiring all centers to follow CACFP nutrition standards. Very few centers participated in CACFP in the past, but $71 \%$ said they would consider it if they were eligible. Lack of understanding about CACFP eligibility was prevalent; only $41 \%$ of the nonparticipating centers knew if they were eligible, including among the centers that indeed qualified on the basis of their nonprofit status or location in a high-poverty area.

Frequently reported reasons for nonparticipation in CACFP were lack of eligible children/children from low-income households (37\% reported), not knowing enough about the program (36\%), not being worth for serving only snacks (27\%), parental preference for sending lunches (16\%), and burdensome paperwork (13\%). To consider participation, centers would need straightforward information about program requirements, eligibility, paperwork, and the application process.

\section{Experience With CACFP Among Participants}

The average length of CACFP participation was around 15 years among the centers and 13 years among the directors/managers (Table 2). The

Table 2. Program Experiences Among Connecticut CACFP-Participating Child Care Centers $(n=96), 2019$

Experiences

General characteristics

Center participation in CACFP, y

Participant experience with CACFP, y

Children on free/reduced-price meals, \%

Completed training to help with CACFP implementation

Main benefits of CACFP participation

Ability to serve nutritious food

Assistance with food costs/meal reimbursements

Providing food to children who do not have it at home

Providing types of food children do not get at home

Opportunities for staff training

Brings in more families to the center

Challenges with CACFP participation $(n=95)$

Difficulty getting parents to return income eligibility forms

Children not eating foods served

Meeting nutrition guidelines within budget

Getting staff to perform meal counts

Insufficient/low meal reimbursements

Insufficient/low snack reimbursements

Monitoring/reviews

Lack of online training and apps to reduce the burden of paperwork

Finding a vendor/catering company

Effects following updates to CACFP meal patterns, n (\%)

Higher nutrition quality of food served

Higher food costs

No change

Increased food waste

Greater staff training needs

Parents more satisfied with meals

Children eat more

Data tracking for attendance/meal counts $(n=95)$

No software, information tracked manually

Microsoft Office Excel

Child Plus

Other packages

CACFP indicates Child and Adult Care Food Program.

most frequently affirmed reasons to participate in the program were altruistic, including the ability to serve nutritious foods (87\%), feeding children without adequate food at home (79\%), and providing types of food that children do not get at home (77\%). Most CACFP centers (81\%) acknowledged meal reimbursements as an important benefit, but many expressed concerns that these did not fully reimburse meal costs. About one-third mentioned staff training as the reason to participate, whereas 23\% thought CACFP participation attracted more families.
There was less agreement on the parts of CACFP that were challenging. The most frequent difficulty affirmed was getting parents to return income eligibility forms, which CACFP centers must collect every year (Table 2). Children not eating the foods served and food waste were a close second, followed by meeting nutrition guidelines within budget, getting staff to perform meal counts at a point of service, insufficient/low meal and snack reimbursements, and state monitoring/reviews. Half of all CACFP centers reported not using any software for data tracking, with 
Table 3. Recommendations to Improve CACFP Experiences by Connecticut CACFP-Participating Child Care Centers $(n=94), 2019$

$\begin{array}{ll}\text { Recommendations } & \mathbf{n}(\%) \\ \text { What could be done to make CACFP participation easier } & \\ \text { More streamlined paperwork } & 42(44.7) \\ \text { Funding ongoing nonfood costs (eg, cooking tools) } & 38(40.4) \\ \text { More educational resources for parents and families } & 31(33.0) \\ \text { Better/free software for planning menus that meet CACFP } & 31(33.0) \\ \quad \text { standards } & \\ \text { Assistance with finding vendors/catering companies that } & 30(31.9) \\ \quad \text { provide quality and affordable meals } & 22(23.4) \\ \text { Apps or other aids to help with purchasing foods/beverages } & 17(18.1) \\ \text { More or different education on the program and child nutrition } & 14(14.9) \\ \text { More support from state staff } & 10(10.6) \\ \text { Facilitated networking with other providers } & \\ \text { What could be done to make CACFP application process easier } & \\ \text { (n= 90) } & 39(43.3) \\ \text { More streamlined paperwork } & 28(31.1) \\ \text { Access to start-up funding to improve kitchen facilities } & 19(21.1) \\ \text { More support from state staff throughout the process } & 18(20.0) \\ \text { Resources for problem-solving when facing a challenging issue } & 14(15.6) \\ \text { Small grants/resources to fund the time cost of applying } & \end{array}$

CACFP indicates Child and Adult Care Food Program.

information on attendance and meal counts tracked using paper records. Perceptions of the revisions to the CACFP meal patterns included better dietary quality of foods served, higher food costs, no changes, and increased food waste.

\section{What Could be Done to Make}

\section{CACFP Application and}

\section{Participation Easier?}

Providers selected streamlining paperwork most often as the change needed to help programs apply and participate in CACFP (Table 3). Other potential helpful changes included availability of funds for ongoing nonfood costs, better/free software for planning menus and educational resources to parents, assistance with finding a catering company/vendor, apps or other aids to help with purchasing CACFPapproved foods/beverages, education on the program, and more support from the state staff. For the application process, desirable changes also included access to start-up funding to improve kitchen facilities, state assistance with problem-solving and small grants to fund the time cost of applying.

\section{Predictors of CACFP \\ Participation}

Centers serving lunch had substantially higher odds of participating in
Observations

${ }^{\mathrm{a}} P<0.05 ;{ }^{\text {b }} P<0.01$.

Note: Significance based on $95 \% \mathrm{Cl}$.
CACFP (adjusted odds ratio, 3.92; $P<0.01$ ), as did centers serving breakfast (adjusted odds ratio, 2.06; $P$ $<0.05$ ). Having a nonprofit status was associated with 2.83 higher odds of CACFP participation $(P<0.01)$, yet other center characteristics were not associated with CACFP participation (Table 4).

Foregone Federal Funds Because of CACFP Underuse

Among licensed CT-based centers serving young children (aged $0-5$ years) and not participating in CACFP, there were 384 nonprofit centers with a licensed capacity of 18,995 children and 117 for-profit centers in high-poverty towns/cities with a licensed capacity of 6,097 children. This study estimated that up to 25,092 young children in Connecticut did not receive CACFP-subsidized meals in FY 2019/20, including 20,299 children who were likely eligible for free or reduced-price meals. On the basis of estimated CACFP underuse among centers serving young children, the state of Connecticut likely missed out on $\$ 30,656,804$ in federal funds in FY 2019-2020.

\section{Table 4. Multivariate Logistic Regression Model of Child Care Center Characteristics' Association With CACFP Participation Among 220 Connecticut Child Care Centers, 2019}

\section{Characteristics}

No. of infants, toddlers, and preschoolers served

Meals and snacks provided by the center

Breakfast

Lunch

Morning snack

Afternoon snack

Nonprofit center

Program participation

State funding (school readiness)

Accept child care subsidies

NAEYC accreditation

Census tract-level sociodemographic characteristics

Population below poverty, \%

Median household income, $\$$

Bachelor's degree or higher, \%

Constant
Adjusted Odds

Ratio $(95 \% \mathrm{Cl})$ of CACFP Participation

-0.0006 ( -0.009 to 0.009$)$

$2.06^{\mathrm{a}}(0.05-4.07)$

$3.92^{\mathrm{b}}(1.96-5.88)$

-1.09 (-2.93 to 0.74$)$

$2.83^{\mathrm{b}}(1.22-4.43)$

$0.74(-0.94$ to 2.43$)$

0.26 ( -1.87 to 2.39$)$

-0.02 ( -1.83 to 1.79$)$

$0.03(-0.05$ to 0.11$)$

-0.00004 ( -0.0001 to 0$)$

$0.02(-0.02$ to 0.07$)$

$-4.23(-9.92$ to 1.47$)$

220
-0.03 ( -3.08 to 3.03$)$

CACFP indicates Child and Adult Care Food Program; $\mathrm{Cl}$, confidence interval; NAEYC, National Association for the Education of Young Children. 
Using a less conservative threshold for area eligibility, the study identified additional 65 for-profit centers serving 3,751 children as potentially eligible for CACFP, increasing the estimated total of foregone federal CACFP meal reimbursements for the state of Connecticut to $\$ 35.2$ million.

\section{DISCUSSION}

This study of CACFP participation in Connecticut center-based programs identified predictors of CACFP participation, center directors' perceptions of key benefits of the program, barriers to participation, and reasons for nonparticipation. Participating centers perceived CACFP as a critical benefit in helping them serve nutritious meals to children, especially those lacking adequate food at home. The CACFP meal reimbursements were important in covering food costs but often seen as insufficient, challenging the providers to meet nutrition guidelines within budget. Many providers found reporting requirements and the program paperwork to be too burdensome, particularly collecting income eligibility forms from families. Among nonparticipating centers, lack of information and limited knowledge about the federal food program for ECE providers remained a major avoidable barrier in expanding CACFP. Although CACFP awareness increased recently, ${ }^{12}$ at least a third of the Connecticut licensed child care centers appeared to remain completely uninformed about CACFP. Increasing CACFP awareness through targeted outreach, clarifying eligibility, limiting paperwork burdens, and highlighting participation benefits may help improve enrollment and extend CACFP's reach.

One of the main predictors of CACFP participation in this sample was a center's nonprofit status suggesting that a particularly large gap in coverage is likely among for-profit centers. Such providers might have misperceptions about their eligibility (eg, CACFP is for nonprofit programs only) or underestimate the number of enrolled children who might qualify for free and reduced-price meals. Targeted outreach to for-profit centers in high-poverty areas is needed to clarify eligibility and benefits and provide technical assistance with the application process and program compliance.

Another predictor of CACFP nonparticipation was lack of meals service. Low reimbursement rates for snacks and high administrative burdens do not provide incentives to participate in CACFP for serving only snacks. Having parents provide lunch or all food is prevalent among CT child care centers, ${ }^{12}$ and potential causes for this pattern are not understood. When centers do not serve any food, state regulations and CACFP subsidies are powerless in ensuring better nutrition and food security for children in these settings. Parent-provided meals were shown to be of low nutritional quality. ${ }^{28}$

Identifying strategies to increase participation in CACFP is needed given the multiple benefits of CACFP participation for children. ${ }^{12-15}$ This analysis estimated that, because of nonparticipation among CACFP-eligible providers serving young children, Connecticut child care centers missed out on $\$ 30.7$ million- $\$ 35.2$ million in federal funds in FY 2019-2020. This estimate is a fraction of total foregone federal funds as it does not include potential reimbursements to family child care homes, after-school programs, and adult day care centers. In comparison, Connecticut received a total of $\$ 18.2$ million in cash payments in FY 2019-2020-half of what eligible nonparticipating centers alone could have received in the same year. ${ }^{27}$ This foregone funding means a higher financial burden on ECE providers and families whose children did not receive CACFP-subsidized meals and snacks, including an estimated 20,300 children from low income households.

This study is subject to several important limitations. The sample was based on child care centers in 1 state and described only centerbased programs. It is possible that centers under-reported challenges related to CACFP participation. The survey aims were described to potential participants as pertaining to understanding CACFP, which might explain a lower response rate among non-CACFP centers. The cost model relied on national data to estimate the proportion of children eligible for free and reducedprice meals. Family income of attending children was not available to measure CACFP eligibility of for-profit centers. Daily attendance was based on several assumptions, although conservative.

\section{IMPLICATIONS FOR RESEARCH AND PRACTICE}

Nonparticipation in CACFP is a lost economic opportunity for thousands of child care providers, which could limit their ability to serve nutritious food to children in need or lead to higher tuition if serving food. Federal funding to assist with food costs for ECE providers can help feed at-risk children, improve their nutrition, and reduce health inequities. ${ }^{12,29-31}$ Federal and state policymakers could play an important role in expanding access to CACFP. A step in this direction was the Access to Healthy Food for Young Children Act, which asked for new funding to strengthen and expand CACFP. ${ }^{32}$

At the federal level, CACFP does not have important flexibilities of the school meal programs, including CEP that allows the provision of free meals to all children in high-poverty areas without laborious collection of family income data. These are the same neighborhoods where, without easy access to CACFP, child care providers and families could be struggling to feed young children in their care. The CEP could have allowed child care programs, just like schools, to serve meals without collecting income eligibility forms-a major burden reported by CACFP-participating programs.

Further research is needed to identify participation barriers and facilitators across states, providers and families. There is also limited understanding of barriers to serving food in child care centers, including access to vendors, equipment and staff availability, cost of compliance with local health and state regulations, tuition implications, and interest in center-provided food among parents. Our study results need further evaluation using samples from other states and preferably nationwide. 
This study estimated that CACFP underutilization among Connecticut child care centers left almost 20,300 children from low income households without CACFP-subsidized meals and cost the state $\$ 30.7$ million in foregone federal funds in FY 2019/2020 alone. Multiple potential avenues exist to increase CACFP participation among eligible providers and to ease the burden of compliance among participating programs. At the federal level, CACFP and the safety net of young children would benefit substantially if it received the same attention and funding as the nutrition of children in the kindergarten through 12th-grade system. Extending current flexibilities of the school meal programs to CACFP can ease the burden of program participation, reduce economic vulnerabilities in the child care system and expand access to nutritious food for millions of youngest American children.

\section{ACKNOWLEDGMENTS}

This study was funded by a grant administered by the Child Health and Development Institute of Connecticut and funded by the Children's Fund of Connecticut, Connecticut Health Foundation, and Newman's Own Foundation. Any opinions, findings, conclusions, or recommendations expressed here are those of the authors and do not necessarily reflect the views of the Child Health and Development Institute. The authors express special thanks to the child care centers that participated in the study and the Connecticut Office of Early Childhood for sharing administrative data on centers' nonprofit status. Helpful suggestions from 2 anonymous reviewers are gratefully acknowledged.

\section{SUPPLEMENTARY DATA}

Supplementary data related to this article can be found at https://doi. org/10.1016/j.jneb.2021.10.001.

\section{REFERENCES}

1. Skinner AC, Ravanbakht SN, Skelton JA, Perrin EM, Armstrong SC. Prevalence of obesity and severe obesity in
US children, 1999-2016. Pediatrics. 2018;141:e20173459.

2. Fox MK, Condon E, Briefel RR, Reidy KC, Deming DM. Food consumption patterns of young preschoolers: are they starting off on the right path? J Am Diet Assoc. 2010;110 (12 suppl):S52-S59.

3. Slining MM, Mathias KC, Popkin BM. Trends in food and beverage sources among US children and adolescents: 1989-2010. J Acad Nutr Diet. 2013;113:1683-1694.

4. Reidy KC, Deming DM, Briefel RR, et al. Early development of dietary patterns: transitions in the contribution of food groups to total energy-Feeding Infants and Toddlers Study, 2008. BMC Nutr. 2017;3:5

5. American Academy of Pediatrics, American Public Health Association, and National Resource Center for Health and Safety in Child Care and Early Education. Preventing Childhood Obesity in Early Care and Education Programs. https://nrckids.org/CFOC/ Childhood_Obesity. Accessed February 10, 2021.

6. Benjamin Neelon SE, Briley ME. American Dietetic Association. Position of the American Dietetic Association: benchmarks for nutrition in child care. J Am Diet Assoc. 2011;111:607615.

7. Kaphingst KM, Story M. Child care as an untapped setting for obesity prevention: state child care licensing regulations related to nutrition, physical activity, and media use for preschoolaged children in the United States. Prev Chronic Dis. 2009;6:A11.

8. Larson N, Ward DS, Neelon SB, Story M. What role can child-care settings play in obesity prevention? A review of the evidence and call for research efforts. J Am Diet Assoc. 2011;111:13431362.

9. US Department of Education, National Center for Education Statistics. National Household Education Surveys Program, Early Childhood Program Participation Survey. https://nces.ed.gov/nhes/young children.asp. Accessed February 10, 2021.

10. US Department of Agriculture, Food and Nutrition Service. Child and Adult Care Food Program (CACFP). https:// www.fns.usda.gov/cacfp. Accessed October 29, 2021.

11. Ritchie LD, Boyle M, Chandran K, et al. Participation in the Child and Adult Care Food Program is associated with more nutritious foods and beverages in child care. Child Obes. 2012; 8:224-229

12. Andreyeva T, Henderson KE. Centerreported adherence to nutrition standards of the Child and Adult Care Food Program. Child Obes. 2018;14:421428.

13. Korenman S, Abner KS, Kaestner R, Gordon RA. The Child and Adult Care Food Program and the nutrition of preschoolers. Early Child Res Q. 2013;28:325-336.

14. Andreyeva T, Kenney EL, O'Connell M, Sun X, Henderson KE. Predictors of nutrition quality in early child education settings in Connecticut. J Nutr Educ Behav. 2018;50:458-467.

15. Erinosho T, Vaughn A, Hales D, Mazzucca S, Gizlice Z, Ward D. Participation in the Child and Adult Care Food Program is associated with healthier nutrition environments at family child care homes in Mississippi. J Nutr Educ Behav. 2018;50:441-450

16. Sigman-Grant M, Christiansen E, Fernandez G, et al. Child care provider training and a supportive feeding environment in child care settings in 4 states, 2003. Prev Chronic Dis. 2011;8: A113.

17. Liu ST, Graffagino CL, Leser KA, Trombetta AL, Pirie PL. Obesity prevention practices and policies in child care settings enrolled and not enrolled in the Child and Adult Care Food Program. Matern Child Health J. 2016; 20:1933-1939.

18. US Department of Agriculture, Food and Nutrition Service. CACFP: National average payment rates, day care home food service payment rates, and administrative reimbursement rates for sponsoring organizations of day care homes (July 1, 2020 - June 30, 2021). https://www.fns. usda.gov/cacfp/fr-072220. Accessed February 10, 2021.

19. Chriqui JF, Leider J, Schermbeck RM, Sanghera A, Pugach O. Changes in Child and Adult Care Food Program (CACFP) practices at participating childcare and education centers in the united states following updated national standards, 2017 2019. Nutrients. 2020;12:2818.

20. Dev DA, Garcia AS, Dzewaltowski DA, et al. Provider reported implementation of nutrition-related practices in childcare centers and family childcare homes in rural and urban Nebraska. Prev Med Rep. 2020;17:101021. 
21. Bauer KW, Chriqui JF, Andreyeva T, et al. A safety net unraveling: feeding young children during COVID-19. Am J Public Health. 2021;111:116-120.

22. United States Census Bureau. 20132017 American Community Survey 5Year Estimates. Year: 2017 Estimates. American Community Survey; 2018.

23. Connecticut State Department of Education. Community Eligibility Provision -2019/20 Eligible Local Educational Agencies. https://portal.ct.gov/-/ media/SDE/Nutrition/CEP/CEP_Approved_Districts_Schools_2019.pdf. Accessed October 29, 2021.

24. U.S. Bureau of Labor Statistics, National Compensation Survey. Paid vacations: Number of annual days by service requirement. https://www.bls.gov/ncs/ ebs/benefits/2017/ownership/private/ table38a.htm. Accessed March 28, 2021.

25. Azor-Martínez E, Gonzalez-Jimenez Y, Seijas-Vazquez ML, et al. The impact of common infections on school absen- teeism during an academic year. $A m \mathrm{~J}$ Infect Control. 2014;42:632-637.

26. US Department of Agriculture, Food and Nutrition Service. CACFP: National average payment rates, day care home food service payment rates, and administrative reimbursement rates for sponsoring organizations of day care homes (July 1, 2019 - June 30, 2020). https://www.fns.usda.gov/cacfp/fr-08 0719. Accessed February 10, 2021.

27. US Department of Agriculture, Food and Nutrition Service. Child nutrition tables. https://www.fns.usda.gov/pd/child-nutrition-tables. Accessed February 10, 2021.

28. Romo-Palafox MJ, Ranjit N, Sweitzer SJ, et al. Dietary quality of preschoolers' sack lunches as measured by the Healthy Eating index. J Acad Nutr Diet. 2015;115:1779-1788.

29. Gurzo K, Lee DL, Ritchie K, et al. Child care sites participating in the federal Child and Adult Care Food Program provide more nutritious foods and beverages. J Nutr Educ Behav. 2020;52:697-704.

30. Heflin C, Arteaga I, Gable S. The child and adult care food program and food insecurity. Soc Serv Rev. 2015;89: 77-98.

31. Library of Congress. S.2501 - Access to Healthy Food for Young Children Act of 2019. https://www.congress.gov/ bill/116th-congress/senate-bill/2501. Accessed February 10, 2021.

32. S.2501 - Access to Healthy Food for Young Children Act of 2019. https:// www.congress.gov/bill/116th-congress/senate-bill/2501. Accessed February $10,2021$.

\section{ORCIDs}

Tatiana Andreyeva: http://orcid.org/ 0000-0002-5143-2378

Mackenzie Cannon: http://orcid.org/ 0000-0003-4319-4768 